\title{
Metastatic Breast Cancer to the Stomach Resembling Early Gastric Cancer
}

\author{
Fumikata Hara ${ }^{a}$ Sachiko Kiyoto ${ }^{a}$ Daisuke Takabatake ${ }^{a}$ \\ Seiki Takashima ${ }^{a}$ Kenjiro Aogi ${ }^{a}$ Shozo Ohsumi ${ }^{a}$ \\ Norihiro Teramoto $^{\text {b }}$ Rieko Nishimurab \\ Shigemitsu Takashima ${ }^{a}$
}

Departments of a Breast Oncology, and bPathology, National Hospital Organization

Shikoku Cancer Center, Matsuyama, Ehime, Japan

\section{Key Words}

Breast cancer - Metastatic gastric tumor

\begin{abstract}
Breast cancer metastases to the stomach are very rare. As characteristics of breast cancer metastases to the stomach, metastases of lobular carcinoma, mainly with signet ring cells, are frequently observed, and they are often difficult to distinguish from a primary gastric cancer with signet ring cells. Moreover, because no characteristic symptoms are shown and they involve a submucosal lesion, it is difficult to make a radiographic diagnosis. However, if a gastric lesion is observed after breast carcinoma surgery, differentiation between a gastric primary lesion and a metastatic lesion is very important in order to determine treatment. We encountered a case that was diagnosed as early gastric cancer discovered using an endoscope 2 years after surgery and which was found to be breast cancer metastasis to the stomach by gross cystic disease fluid protein (GCDFP) and cytokeratin (CK) 7/20 immunostaining of the biopsy tissue. Here, we report our findings of this unique case.
\end{abstract}

\section{Introduction}

The common sites of breast carcinoma metastases include local and distant lymph nodes, bone, lung, liver and brain, with metastases to the gastrointestinal tract being rare including to the stomach, large intestine, and small intestine. Most reports on breast cancer metastases to the stomach consist of a series of autopsy cases, case reports, and a few actual cases [1-3]. 
According to a report on these few cases, as characteristics of breast cancer metastasis to the stomach, mainly lobular carcinoma metastases with signet ring cells are frequently observed, and they are often difficult to differentiate from signet ring cells of gastric cancer [4]. Moreover, because they occur some time after surgery, show no typical symptoms, and take the form of crawling under the mucosa, it is difficult to differentiate between primary and metastatic forms from endoscopic, radiographic, and pathological perspectives $[5,6]$. Therefore, when a tumor mass was found in the stomach after breast carcinoma surgery, it was very difficult to differentiate between primary gastric cancer and a metastatic tumor. However, in the case of a metastatic tumor, systemic therapy is necessary and, as a result, making an accurate differential diagnosis plays an important role in determining treatment. We encountered a case that was diagnosed as early gastric cancer using an endoscope 2 years after surgery and was found to be breast cancer metastasis to the stomach by immunostaining of the biopsy tissue. Therefore, we here report our findings.

\section{Case Report}

A 74-year-old female became aware of a lump in her left breast and visited our hospital. In the left C region, a mass $1.8 \mathrm{~cm}$ in size was observed. The axillary lymph nodes were not palpable. According to the results of a core needle biopsy, a diagnosis of an infiltrating ductal breast carcinoma was made. Breast-conserving surgery and a sentinel lymph node biopsy were performed. Postoperative pathological diagnosis showed grade 3, $1.3 \times 1.0-\mathrm{cm}$ invasive ductal carcinoma. The tumor was negative for estrogen receptor, progesterone receptor, and HER2. Three lymph nodes were involved. At the patient's request, only breast irradiation was performed as a postoperative treatment. She had a previous history of chronic gastritis and underwent regular gastroscopic examinations, but IIa+IIc polyps 5-6 $\mathrm{mm}$ in size were observed on the anterior wall of the lower gastric body on gastroscopic examination. Macroscopically, early gastric cancer was suspected ( $\underline{\text { fig. } .1 a)}$ ). Upon endoscopic ultrasound, a rounded low echoic lesion was observed in the submucosa (fig. 1b). The same part was biopsied, and HE staining revealed growth of atypical cells with various sized circular-shaped nuclei mainly in the submucosa. Furthermore, immunostaining was performed and showed cytokeratin (CK) 7(+), CK20(-), and gross cystic disease fluid protein (GCDFP) 15(+), and therefore, it was believed that it was breast carcinoma (fig. 2). A PET examination was performed as a systemic examination, and accumulation of FDG was observed in the right supraclavicular fossa lymph nodes. The results of fine needle aspiration cytology showed metastasis. Gastric metastasis could not be detected upon PET. As systemic therapy, weekly paclitaxel was administered but was not effective, and subsequently AC regimen was performed, yielding clinically complete remission both in the lymph nodes and the gastric tumor mass. However, meningeal dissemination was observed during a follow-up, and the patient passed away 1 year after undergoing the initial treatment for the recurrence.

\section{Discussion}

The most common metastatic sites of breast carcinoma are the local and distant lymph nodes, bone, lung, liver and brain. Breast carcinoma metastases to the gastrointestinal tract as first metastatic site are extremely rare. However, according to a report on breast cancer metastases to the stomach in autopsy cases, it was found in 2 to $18 \%$ of cases [2]. On the other hand, according to a report of clinical cases by Taal et al. [3], the morbidity rate of breast cancer metastasis to the stomach is approximately $0.3 \%$. It is believed that this difference may be due to underestimation because the symptoms of breast cancer metastases to the stomach were nonspecific, including indigestion, lack of appetite, and epigastric pain, and, therefore, no close examination such as by endoscope was performed unless serious symptoms were observed, resulting in metastases being overlooked $[3,7]$. Furthermore, there are some reasons that make diagnosis difficult. The endoscopic finding of a typical gastric metastasis is diffuse intramural infiltration imitating linitis 
plastica, $50 \%$ of which involves mucosal abnormalities that are difficult to differentiate as normal or benign. As a result, many cases are not diagnosed as breast cancer metastasis to the stomach until surgery is performed. Furthermore, because tumors are located in deep mucosal tissue, it is not rare for a biopsy to show a false negative [3-6]. Therefore, in the past, there have not been any studies on diagnostic performance for gastric metastasis using endoscopic ultrasound, but this method may be useful in making a morphological diagnosis and selecting an appropriate biopsy location [8].

For an accurate differential diagnosis between primary gastric cancer and breast cancer metastasis to the stomach, immunostaining methods are recommended. Van Velthuysen et al. [9] reported that second-generation estrogen receptors are not observed in the expression of gastric cancer and are useful in diagnosing breast cancer metastases to the stomach. However, when estrogen receptors of the primary lesion are negative, as in the present case, they are not useful. GCDFP-15 is a substance found in breast cysts and the plasma of patients with breast carcinoma, and antibodies of this may be useful for accurately diagnosing whether a metastatic tumor is primary breast carcinoma. According to some reports, their sensitivity is $55-76 \%$ and their specificity is $95-100 \%$ $[10,11]$. It has been reported that the immunostaining of CK7 and 20 is also useful for making a differential diagnosis in order to distinguish this case from gastric cancer [11, $12]$.

The present case is of a breast ductal carcinoma metastasis to the stomach, but it has been reported that breast carcinoma metastases to the gastrointestinal tract are frequently observed in lobular carcinoma. Lobular breast carcinoma frequently takes the form of a signet ring and may be confused with primary gastric signet ring cells [3, 4].

According to a case series of 73 patients by McLemore et al. [13], the median survival period was 28 months, and anticancer agents and hormone treatment were effective, but surgery did not improve the prognosis. Therefore, treatment should be limited to palliative bypass for obstruction to the passage due to gastric obstruction.

In conclusion, when a patient with a previous history of breast carcinoma complains of digestive symptoms or is diagnosed as having primary gastric cancer, it is necessary to consider the possibility of breast cancer metastasis to the stomach. For a differential diagnosis, immunostaining is recommended, and when a diagnosis of breast cancer metastasis to the stomach is made, systemic therapy is necessary. 


\begin{tabular}{c|l|l|l}
$\begin{array}{c}\text { Cose Reports in } \\
\text { Onculagy }\end{array}$ & $\begin{array}{l}\text { Case Rep Oncol 2010;3:142-147 } \\
\text { D01: 10.1159/000313923 }\end{array}$ & Published online: April 29, 2010 & $\begin{array}{l}\text { O 2010 S. Karger AG, Basel } \\
\text { ISSN 1662-6575 } \\
\text { www.karger.com/cro }\end{array}$ \\
\hline
\end{tabular}

Fig. 1. Endoscopic view of gastric metastasis of breast cancer, mimicking IIa+IIc early gastric cancer (a). On endoscopic ultrasound a rounded low-echoic lesion was observed in the submucosa (b).

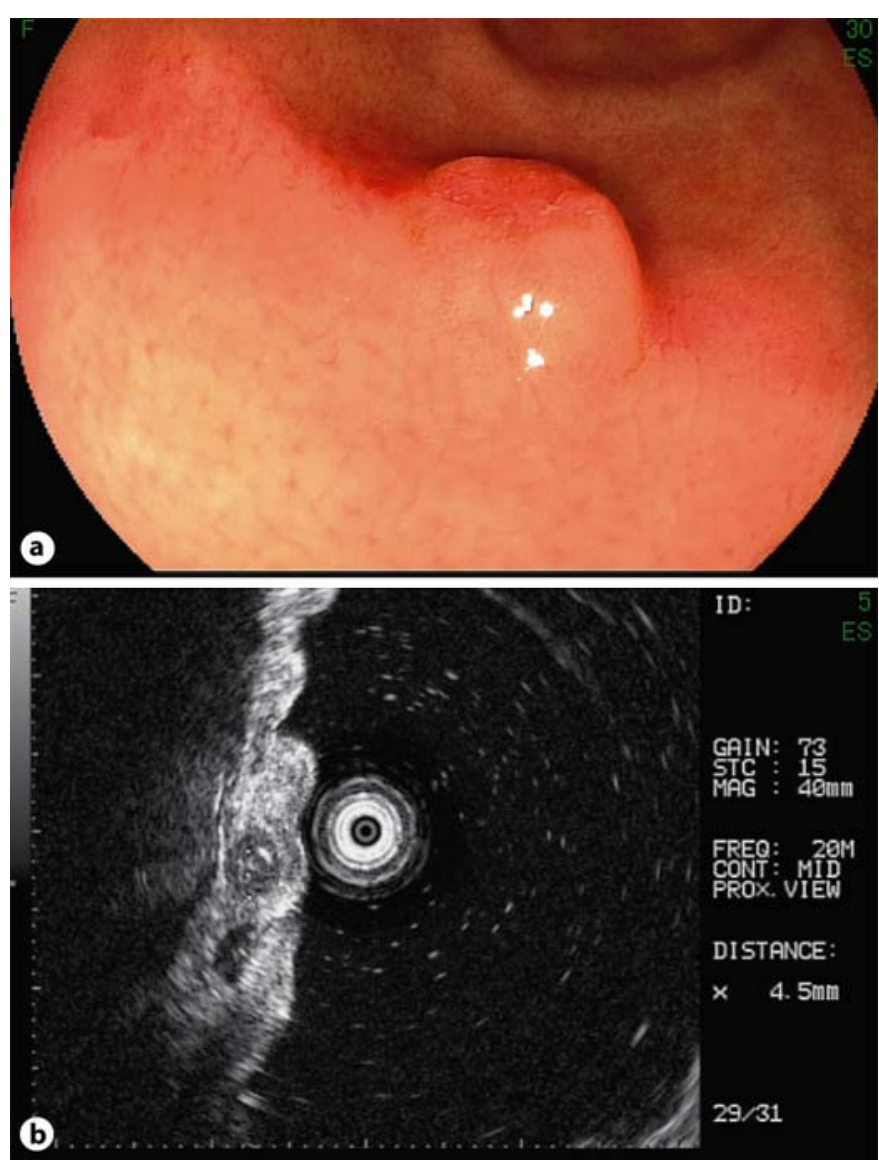




\begin{tabular}{c|l|l|l}
$\begin{array}{c}\text { Case Reports in } \\
\text { Oncolady }\end{array}$ & $\begin{array}{l}\text { Case Rep Oncol 2010;3:142-147 } \\
\text { D0I: 10.1159/000313923 }\end{array}$ & Published online: April 29, 2010 & $\begin{array}{l}\text { O 2010 S. Karger AG, Basel } \\
\text { ISSN 1662-6575 } \\
\text { www.karger.com/cro }\end{array}$ \\
\hline
\end{tabular}

Fig. 2. HE staining of gastric biopsy specimen revealed a poorly differentiated adenocarcinoma with signet ring cell morphology (a). Immunohistochemistry showed strongly positive staining for CK7, negative staining for CK20, and positive staining for GCDFP-15 (b).

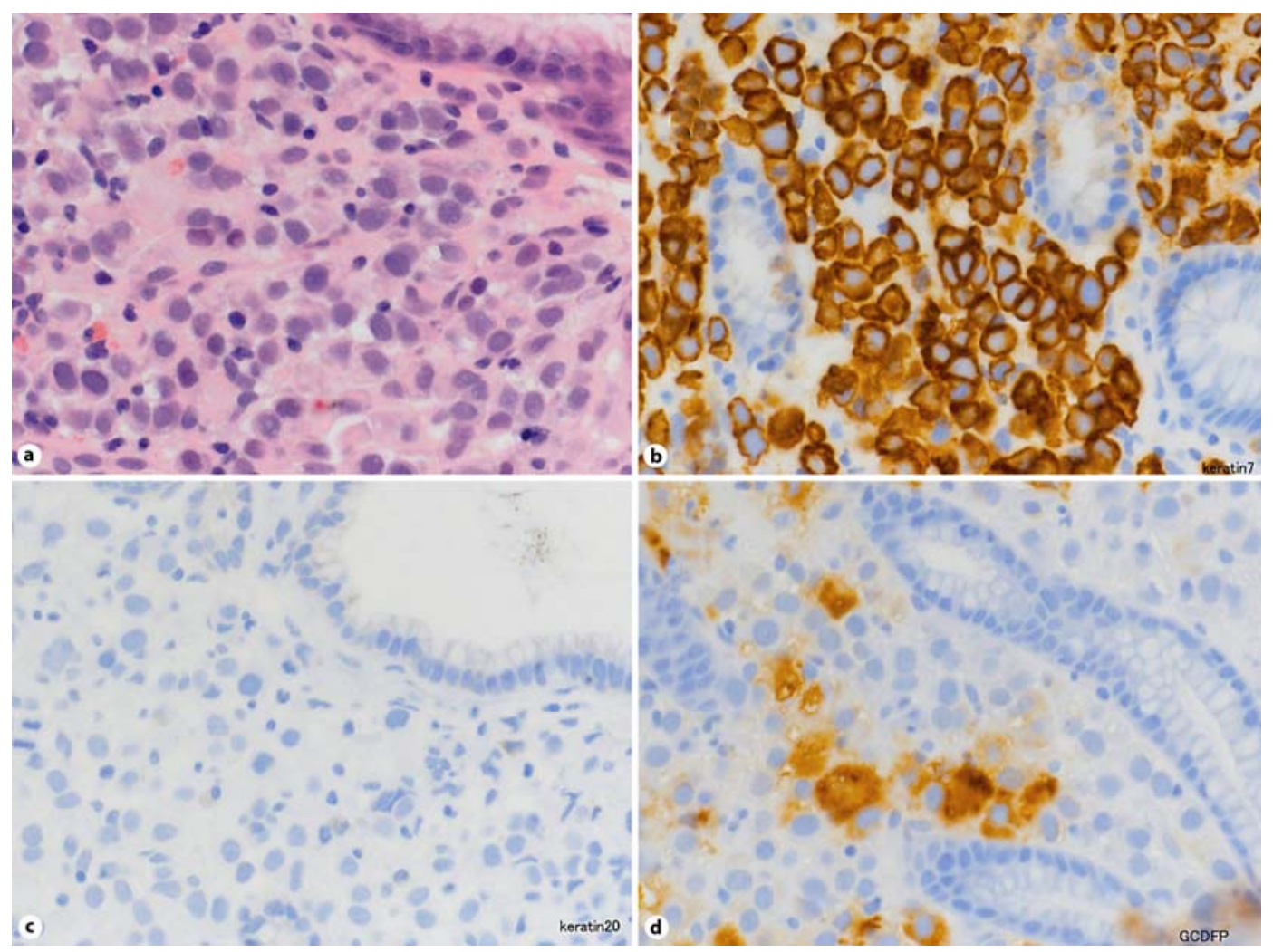




\begin{tabular}{c|l|l|l}
$\begin{array}{c}\text { Cose Reports in } \\
\text { Ondity }\end{array}$ & $\begin{array}{l}\text { Case Rep Oncol 2010;3:142-147 } \\
\text { Dol: } 10.1159 / 000313923\end{array}$ & Published online: April 29, 2010 & $\begin{array}{l}\text { @ 2010 S. Karger AG, Basel } \\
\text { ISSN 1662-6575 } \\
\text { www.karger.com/cro }\end{array}$ \\
\hline
\end{tabular}

\section{References}

-1 Menuck LS, Amberg JR: Metastatic disease involving the stomach. Am J Dig Dis 1975;20:903-913.

2 Davis HL Jr, Murray RK, Korbitz BC: Breast carcinoma metastatic to the stomach. Report of a case in a male and review of an autopsy series. Am J Dig Dis 1968;13:868-873.

-3 Taal BG, Peterse H, Boot H: Clinical presentation, endoscopic features, and treatment of gastric metastases from breast carcinoma. Cancer 2000;89:22142221.

4 Raju U, Ma CK, Shaw A: Signet ring variant of lobular carcinoma of the breast: a clinicopathologic and immunohistochemical study. Mod Pathol 1993;6:516-520.

5 Taal BG, den Hartog Jager FC, Steinmetz R, Peterse H: The spectrum of gastrointestinal metastases of breast carcinoma: II. The colon and rectum. Gastrointest Endosc 1992;38:136-141.

-6 Madeya S, Börsch G: Gastrointestinal metastases of breast carcinoma. Gastrointest Endosc 1993;39:103-104.

7 Ferri LE, Onerheim R, Emond C: Linitis plastica as the first indication of metastatic lobular carcinoma of the breast: case report and literature review. Can J Surg 1999;42:466-469.

-8 Lorimier G, Binelli C, Burtin P, Maillart P, Bertrand G, Verriele V, Fondrinier E: Metastatic gastric cancer arising from breast carcinoma: endoscopic ultrasonographic aspects. Endoscopy 1998;30:800-804.

-9 van Velthuysen ML, Taal BG, van der Hoeven JJ, Peterse JL: Expression of oestrogen receptor and loss of E-cadherin are diagnostic for gastric metastasis of breast carcinoma. Histopathology 2005;46:153-157.

10 Wick MR, Lillemoe TJ, Copland GT, Swanson PE, Manivel JC, Kiang DT: Gross cystic disease fluid protein-15 as a marker for breast cancer: immunohistochemical analysis of 690 human neoplasms and comparison with alpha-lactalbumin. Hum Pathol 1989;20:281-287.

-11 O'Connell FP, Wang HH, Odze RD: Utility of immunohistochemistry in distinguishing primary adenocarcinomas from metastatic breast carcinomas in the gastrointestinal tract. Arch Pathol Lab Med 2005;129:338-347.

$\checkmark 12$ Tot T: Cytokeratins 20 and 7 as biomarkers: usefulness in discriminating primary from metastatic adenocarcinoma. Eur J Cancer 2002;38:758-763.

-13 McLemore EC, Pockaj BA, Reynolds C, Gray RJ, Hernandez JL, Grant CS, Donohue JH: Breast cancer: presentation and intervention in women with gastrointestinal metastasis and carcinomatosis. Ann Surg Oncol 2005;12:886-894. 